\title{
Funding 'elite' science
}

\section{Changes to key Wellcome Trust funding schemes spark concern about shrinking sources of funding for univer- sity laboratories in the United Kingdom.}

Earlier this year, in an interview with a British newspaper, Paul Nurse, now the President of the Royal Society, touched a nerve within the science establishment in the UK when he called for a reform of research-funding allocation. Nurse proposed a model that would identify a select pool of 'elite' researchers for generous long-term funding to allow them to pursue bold and visionary research. He cited the strategy of the Howard Hughes Medical Institute (HHMI) in the USA, renowned for its "people not projects" motto, as a compelling mechanism for developing a cadre of exceptional scientists. HHMI investigators are selected on the basis of an outstanding research record and future promise rather than the merits of a specific research proposal. They are appointed to a renewable five-year term at a host institution and are free to alter the direction of their research programme unfettered by funding agency restrictions on the evolution of their research. This strategy has certainly worked well for the HHMI which can take pride in an impressive roster of HHMI-funded investigators who are at the forefront of research in their various areas. Last year, the Wellcome Trust, the largest charity funding biomedical research in the UK, unveiled their proposal to introduce changes to their funding programmes in 2010, also focusing on people rather than projects when distributing grants to biomedical researchers.

From October 2010 onwards, the Trust will introduce the Investigator Awards, which are designed to promote research excellence by supporting the best and the brightest through two funding schemes, the New Investigator Awards and Senior Investigator Awards. The Investigator Awards will replace several schemes including the Project and Programme grants that were the mainstay of the Wellcome Trust's support for basic research funding. Both categories of Investigator Awards aim to attract applicants of high calibre with a demonstrated track record of distinction in research. The Awards promise significantly larger grants for longer periods of time: seven years, compared with the three to five years of support provided by the Project and Programme grants. Applications will be subject to peer review, and candidates will be assessed on individual criteria, such as the strength of their previous research contributions, the significance of the proposed research and approaches, and the suitability of the research environment, followed by an interview of shortlisted candidates. By supporting outstanding candidates in this manner, the Trust hopes to spur innovation and creativity in research.

Project grants from most funding agencies in the UK have an expiration date of three years. As a result, researchers often spend inordinate amounts of time charting the bureaucracy of various funding organizations as they move from one short funding cycle to another, which significantly detracts from their ability to focus on, and develop their research. Many funding agencies do offer five-year programme grants, but these are often not available to new researchers who do not already have a strong independent research track record. Longer funding cycles, particularly for new and mid-level investigators who are still establishing a research programme, is certainly a positive development. However, there is considerable concern that the phasing out of the Wellcome Trust Projects and Programme grants that supported hypothesis-driven research with focused goals will deprive many smaller laboratories of much-needed support. Researchers who have previously been supported by these funding streams may no longer be competitive for the new Investigator Awards, which are likely to have more exacting standards. A squeeze on the budgets of research councils (public bodies that funnel government funds into research), such as the MRC and the BBSRC, because of cuts in the UK government's budget for funding life science research, combined with stiffer competition for resources from non-governmental agencies such as Cancer Research UK, has already strained existing funding schemes. In short, money is tight, and the dismantling of the Trust's Projects and Programmes scheme will certainly exacerbate the situation. The Wellcome Trust is a prominent and influential organization, and concern that other funding organizations may follow in its footsteps, further limiting available resources, is understandable. Another concern is that the Investigator Awards and similar schemes will propagate a trend of favouring large wellestablished laboratories that already have several secure sources of funding, resulting in a situation of the 'rich getting richer' while funding streams for smaller laboratories dry up.

Funding bodies such as the European Research Council, founded in 2007, share the Wellcome Trust's vision for nurturing scientific excellence in Europe by supporting the most creative researchers and encouraging them to engage in frontier-breaking research (http:// www.nature.com/ncb/journal/v12/n4/full/ncb0410-307.html). Certainly, more money for a longer timeframe coupled with greater flexibility could enable researchers to pursue long-term, exploratory research programmes, free from the relentless pressures of having to deliver results within unrealistic timeframes. But as the funding landscape becomes increasingly competitive, and more money is earmarked for the very best and for those engaging in 'blue skies' research, it is imperative to ensure that there is adequate funding available for existing laboratories with a productive track record of pursuing hypothesis-driven research. Of course, the responsibility for securing the health of biomedical research in the UK rests squarely with the government. The government must consider these shifts in the funding landscape and respond appropriately to ensure that the research councils are sufficiently financed in the next budget. Doing so is crucial for maintaining and developing the next generation of UK scientists. 